\title{
Study on Cutting Processing Technology of Titanium Alloy
}

\author{
Zhang Yongdi ${ }^{1, \mathrm{a}}$,Dong Rui ${ }^{2, \mathrm{~b}}$,Zhao Yuejing ${ }^{1, \mathrm{c}}$,Wang Yang ${ }^{1, \mathrm{~d}}$ \\ ${ }^{1}$ School of Mechanical Engineering, Hebei University of Science \& \\ Technology, Shijiazhuang, China \\ ${ }^{2}$ Capital Space Machinery Corporation (CSMC), Beijing, China \\ ${ }^{a}$ zhydi@yeah.net, ${ }^{b} 13671066310 @ 139 . c o m$, \\ czhaoyj74@163.com, ${ }^{d} 1012229883 @ q q . c o m$
}

\begin{abstract}
Titanium alloy as the main material of aerospace vehicles, its application is becoming more and more widely. Because of its high intensity, active chemistry and low elasticity, the difficulty of processing is attracting more attention in machining field. The machinability of titanium alloy is analyzed, and with actual experience, the cutting tool material, cutting tool geometry parameters and machining process is selected reasonably, so that can optimize machining parts.

Keywords: titanium alloys; cutting processing technology; cutting tool geometry parameter
\end{abstract}

\section{Introduction}

Titanium alloy with low density, high strength, high temperature resistance, high corrosion resistance and other excellent characteristics, has been the main structural material for aerospace vehicle. In the early 1980s, the application of titanium alloy in aircraft has already reached above 30\% [1], and increased year by year. The application range is enlarged further, from military to civilian, used in aerospace, marine, chemical facilities and light industry etc..

With the improving of the workshop production capacity at present, the application technology especially titanium alloy processing technology matures, the proportion of titanium alloy in design the product parts is more and more big, the proportion of processing gradually improve. In YF - 75, YF - 75 - d, YF - 77 and other types of turbine pump, the proportion reached nearly $30 \%$.But due to its high strength, high chemical activity and low elastic modulus, titanium alloy is difficult to machine, to a great extent, restricts the titanium alloy products processing quality and production efficiency, is attracting more and more attention in the field of mechanical processing. 


\section{The processing features of titanium alloys}

\subsection{Small deformation coefficient, big contact stress}

The ductility of titanium alloy is small, and its cutting deformation coefficient is less than or close to 1 , is $1 / 3$ of ordinary carbon steel, especially after the occurrence of chemical reaction with the surrounding gas at high temperature, ductility reduces, hardness and shear angle increases, the chip and the rake face contact length is very small, easy to wear. The stress of tool nose and cutting edge big, which is a remarkable characteristic of titanium alloy cutting.

\subsection{Small coefficient of thermal conductivity, high cutting temperature}

As the thermal conductivity of titanium alloy is very small, respectively is $1 / 5 \sim 1 / 745$ of steel and 1/16 of $\mathrm{Al}$ [2], combined with the contact area of the chip and tool cutting is small, cutting heat concentrates and difficult to disperse, so that the cutting temperature is high, this is not only easy to cause the workpiece burn, but also lead to the formation of a surface oxidation hardening layer, softening cutting tool materials and accelerating tool wear.

\subsection{Small elastic modulus, large elastic recovery}

The elastic modulus of titanium alloy is about $1 / 2$ of steel, when cutting is easy to produce large cutting deformation and elastic recovery, especially the springback of thin wall parts processing more serious[3]. Contact area of the workpiece surface and the flank between increases, not only make the knife surface serious tool wear, but also cause the bending deformation, vibration, affect the machining accuracy.

\subsection{Large chemical activity, strong hardening tendency}

$600^{\circ} \mathrm{C}$ above high temperature easily can lead to generate strong chemical reaction between titanium alloy with oxygen, nitrogen, hydrogen and other gases, the thickness of 0.1 to $0.15 \mathrm{~mm} \mathrm{TiO}_{2}$, TiN and other hard brittle layer, and the plastic deformation and cutting can also cause surface hardening, cause wear on tool, and generate $\mathrm{TiO}_{2}$, TiN and other hard brittle layer, at the same time the plastic deformation of cutting can also cause surface hardening and wear on tool.

\subsection{Large friction coefficient, high speed}

The friction coefficient between titanium alloy and tool material is greater than carbon steel, but deformation coefficient is particularly small, the friction velocity of swarf along the rake face is high, in addition, in $300^{\circ} \mathrm{C}$ above high temperature is extremely easy to have the sticking phenomenon ${ }^{[4]}$, so that the cutting tool wear easily, low life. 


\section{The selection of the tool and the geometry parameters}

Because the titanium alloy with high hardness, high toughness, low thermal conductivity, low plasticity characteristics, belongs to the difficult-to-machine material, so the machining process will cause big cutting force, high cutting temperature and low tool life. In order to achieve the best cutting effect, the cutter, cutting thickness, cutting fluid and other aspects should be considered. The tool is particularly important, is the key of titanium alloy cutting[5].

\subsection{The selection of the tool in titanium alloys machining}

The primary factor choosing titanium alloy cutting tool material is to reduce the cutting temperature and reduce tool wear. The general performance requirements of cutting tool material are: high hardness and wear resistance, sufficient strength and toughness, high heat resistance, good manufacturability and economy etc.. In titanium alloy processing, high performance high speed steel is often used, especially W2Mo9Cr4VCo8 (M42). This is a cobalt superhard high speed tool steel, has good comprehensive properties, its hardness can reach 85 86.6HRA, $600{ }^{\circ} \mathrm{C}$ high temperature hardness is $78.5 \mathrm{HRA}$. Therefore, it allows higher cutting speed, its grindability is good, suitable for precise complex cutting tool.

In titanium alloy processing, hard alloy cutter is most widely used. Because of the small chemical affinity between titanium alloy, and good thermal conductivity, high strength. Hard alloy is composed of refractory metal carbide (such as WC, TiC, TaC, NbC etc.) and metal binder (such as Co, Ni etc.), and then made by powder metallurgy method. Due to the hard alloy contains large amounts of metal carbides, they have high melting point, high hardness, good chemical stability, good thermal stability and other characteristics, therefore, the hardness of the hard alloy, wear resistance, heat resistance are very high. Commonly used cemented carbide hardness can reach $89 \sim 93 \mathrm{HRA}$, higher than high speed steel $(83 \sim 86.6 \mathrm{HRA})$. The cutting in $800^{\circ} \mathrm{C} \sim 1000^{\circ} \mathrm{C}$ can also happen, so the durability of the tool and the cutting speed have been greatly enhanced [6].

WC-Co (YG) hard alloy tool is one of the most used cutting tools in the workshop processing, such as YG3, YG6, YG6X, YG8, mainly YG6X, the other is WC-TiC-Co (YT) hard alloy tool, mainly YT15, YT alloy has the outstanding advantages of good heat resistance, But TiC content rise, makes the thermal conductivity and grinding performance decreased. The chemical composition and mechanical properties of commonly used cemented carbide tools are shown in tab.1.

Tab.1 Chemical composition and mechanical properties of cemented carbide tools

\begin{tabular}{c|c|c|c|c}
\hline $\begin{array}{c}\text { cat } \\
\text { eg } \\
\text { or }\end{array}$ & mark & $\begin{array}{c}\text { Chemical } \\
\text { composition } \\
\%\end{array}$ & $\begin{array}{c}\text { physical } \\
\text { property }\end{array}$ & Mechanical properties \\
\hline
\end{tabular}




\begin{tabular}{|c|c|c|c|c|c|c|c|c|c|c|c|c|c|}
\hline \multicolumn{14}{|l|}{$\mathrm{y}$} \\
\hline & & $\begin{array}{l}\text { W } \\
\text { C }\end{array}$ & $\begin{array}{l}\mathrm{T} \\
\mathrm{a} \\
\mathrm{C}\end{array}$ & $\begin{array}{l}\mathrm{T} \\
\mathrm{i} \\
\mathrm{C}\end{array}$ & $\begin{array}{l}\mathrm{C} \\
\mathrm{o}\end{array}$ & $\begin{array}{c}\text { De } \\
\text { nsi } \\
\text { ty } \\
\text { g/ } \\
\text { C } \\
\mathrm{m}^{2}\end{array}$ & $\begin{array}{l}\text { Ther } \\
\text { mal } \\
\text { con } \\
\text { duct } \\
\text { ivity } \\
\mathrm{W} /( \\
\mathrm{M} \cdot \\
\left.{ }^{\circ} \mathrm{C}\right)\end{array}$ & $\begin{array}{l}\text { The } \\
\text { coe } \\
\text { ffic } \\
\text { ient } \\
\text { of } \\
\text { ther } \\
\text { mal } \\
\text { exp } \\
\text { ans } \\
\text { ion }\end{array}$ & $\begin{array}{c}\mathrm{Ha} \\
\text { rdn } \\
\text { ess } \\
\text { HR } \\
\text { C }\end{array}$ & $\begin{array}{l}\text { Be } \\
\text { ndi } \\
\text { ng } \\
\text { str } \\
\text { en } \\
\text { gth } \\
\text { Gp } \\
\text { a }\end{array}$ & $\begin{array}{c}\text { Com } \\
\text { pres } \\
\text { sive } \\
\text { stren } \\
\text { gth } \\
\text { Gpa }\end{array}$ & $\begin{array}{c}\text { M } \\
\text { od } \\
\text { ulu } \\
\text { s } \\
\text { of } \\
\text { ela } \\
\text { sti } \\
\text { cit } \\
\text { y } \\
\text { Gp } \\
\text { a }\end{array}$ & $\begin{array}{c}\text { Imp } \\
\text { act } \\
\text { toug } \\
\text { hnes } \\
\text { sKJ/ } \\
\mathrm{m}^{2}\end{array}$ \\
\hline \multirow{5}{*}{$\begin{array}{l}\text { W } \\
\mathrm{C} \\
+ \\
\text { Co }\end{array}$} & $\begin{array}{c}\text { YG3 } \\
X\end{array}$ & $\begin{array}{l}9 \\
6 \\
5 \\
5\end{array}$ & $\begin{array}{l}< \\
0 \\
\dot{5}\end{array}$ & & 3 & $\begin{array}{c}15 \\
.0 \\
\sim \\
15 \\
.3\end{array}$ & & 4.1 & $\begin{array}{c}91 . \\
5\end{array}$ & 1.1 & $\begin{array}{c}5.4 \\
\underset{5.6}{\sim}\end{array}$ & & \\
\hline & $\begin{array}{c}\text { YG6 } \\
\mathrm{X} \\
(\mathrm{K} \\
05)\end{array}$ & $\begin{array}{l}9 \\
3 \\
\dot{5}\end{array}$ & $\begin{array}{l}< \\
0 \\
\dot{5}\end{array}$ & & 6 & $\begin{array}{c}14 \\
.6 \\
\sim \\
15 \\
.0\end{array}$ & 79.6 & 4.4 & 91 & 1.4 & $\begin{array}{c}4.7 \\
5.1\end{array}$ & & $\sim 20$ \\
\hline & YG6 & $\begin{array}{l}9 \\
4\end{array}$ & & & 6 & $\begin{array}{c}14 \\
.6 \\
\sim \\
15 \\
.0\end{array}$ & 79.6 & 4.5 & $\begin{array}{c}89 . \\
5\end{array}$ & $\begin{array}{c}1.4 \\
5\end{array}$ & 4.6 & $\begin{array}{c}63 \\
0 \\
\sim \\
64 \\
0\end{array}$ & $\sim 30$ \\
\hline & $\begin{array}{l}\text { YG8 } \\
(\mathrm{K} \\
20)\end{array}$ & $\begin{array}{l}9 \\
2\end{array}$ & & & 8 & $\begin{array}{c}14 \\
.5 \\
\sim \\
14 \\
.9 \\
\end{array}$ & 75.4 & 4.5 & 89 & 1.5 & 4.47 & $\begin{array}{c}60 \\
0 \\
\sim \\
61 \\
0\end{array}$ & $\sim 40$ \\
\hline & $\begin{array}{l}\text { YS2( } \\
\text { YG1 } \\
0 \mathrm{H})\end{array}$ & $\begin{array}{l}9 \\
0\end{array}$ & & & $\begin{array}{l}1 \\
0\end{array}$ & $\begin{array}{c}14 \\
.3 \\
\sim \\
14 \\
.6\end{array}$ & & & $\begin{array}{c}91 . \\
5\end{array}$ & 2.2 & & & \\
\hline $\begin{array}{l}\mathrm{W} \\
\mathrm{C} \\
+ \\
\mathrm{Ti} \\
\mathrm{C}+ \\
\mathrm{Co}\end{array}$ & $\begin{array}{c}\text { YT1 } \\
5\end{array}$ & $\begin{array}{l}7 \\
9\end{array}$ & & $\begin{array}{l}1 \\
5\end{array}$ & 6 & $\begin{array}{c}11 \\
.0 \\
\sim \\
11 \\
.7\end{array}$ & 33.5 & $\begin{array}{c}6.5 \\
1\end{array}$ & 91 & $\begin{array}{c}1.1 \\
5\end{array}$ & 3.9 & $\begin{array}{c}52 \\
0 \\
\sim \\
53 \\
0\end{array}$ & \\
\hline
\end{tabular}




\subsection{The selection of the geometry parameters in titanium alloys machining}

Anterior angle $\gamma_{0}$. The cutting force and cutting heat concentrated near the cutting edge when titanium alloy cutting. In order to improve heat dissipation conditions, the surface contact length between the swarf and the front cutter should be increased, so that can strengthen the cutting edge, and smaller rake angle should be used, generally $\gamma_{0}=5^{\circ} \sim 10^{\circ}$. Hard alloy tool machining titanium alloy often uses negative chamfer to enhance the cutting edge chamfer, reduce the tool breakage. As a general rule, the negative chamfer parameters commonly are: $b_{\gamma 1}=0.03 \sim 0.1 \mathrm{~mm}, \gamma_{01}=-10^{\circ} \sim 0^{\circ}$

Relief angle $\alpha_{0}$. The elastic recovery of titanium alloy is big, in order to reduce the friction between the flank surface of cutting tool and the machined surface, larger relief angle should be used. In the actual production of titanium alloy cutting, relief angle is $15^{\circ}$ around the highest degree of tool life, the cutting edge is relatively sharp, so the relief angle of the titanium alloy machining tool generally uses $15^{\circ}$ as a benchmark selection.

Tool cutting edge angle $k_{\gamma}$ and tool minor cutting edge angle $k_{\gamma}{ }^{\prime} \cdot$ There are three functions of $k_{\gamma}$ and $k_{\gamma}{ }^{\prime}$ [7], the first is the influence of cutting edge of load and strength, the impact of heat conditions and then affect the tool life, the second is directly affecting the roughness of the machined surface, The third is the influence of process system rigidity. Titanium alloy cutting should minimize tool cutting edge angle to decrease the load on the cutting edge, increase the cooling area. So rough machining, $k_{\gamma}$ in general be selected between $30^{\circ}$ and $45^{\circ}$, fine finish machining and cutting thin pieces $k_{\gamma}$ be chosen a large value, generally $75^{\circ}$ to $90^{\circ}$.In general $k_{\gamma}{ }^{\prime}$ should choose a small value. $k_{\gamma}$ ' usually be selected between $5^{\circ}$ to $15^{\circ}$. Take a larger value when rough machining, finish machining of small value.

Tool cutting edge inclination angle $\lambda_{S} . \lambda_{S}$ has a great impact on the swarf flow direction, cutting edge sharpness, edge strength and heat dissipation. Titanium alloy processing will cause the cutting force and cutting heat concentration, in order to strengthen the blade, and ensure the durability of cutting tools, the general choice is the absolute value smaller $\lambda_{S}$, rough machining according to the circumstances, generally make choice between $-5^{\circ}$ to $5^{\circ}$, fine machining generally $\lambda_{S}=0^{\circ}$.

Nose of tool. The nose of tool has low strength, and heat dissipation condition is not good, so the cutting temperature of the nose of tool is highest, it is easy to wear. Therefore, the titanium alloy cutting tool nose generally do not allow grinding sharp corners or straight line type transition edge, but needs to be 
grinded out arc transition edge, and generally the knifepoint arc radius $r=0.5 \sim$ $1.5 \mathrm{~mm}$.

\subsection{The improvement measures of Titanium alloy cutting tool grinding quality}

Diamond grinding wheel can be used to grind, and can ensure the sharpness of the cutting edge, the cutting tool surface smooth, front and flank surfaces roughness less than Ra 0.4 , the cutting edge part is not allowed to have a slight gap. The diamond or $\mathrm{SiC}$ oilstone can be used to grind inverted edge (back knife), in order to eliminate the curf generated in grinding, so that make the cutting edge smooth, improve the tool abrasion resistance, enhance the blade intensity [8].

\section{Titanium alloy common processing technology and examples}

In the titanium alloy processing, the reasonable selection of tool materials and geometric parameters is very important, in addition to the cutting parameters also should be optimized, and the reasonable processing methods should be chosen etc.. The present processing technology usually adopted in workshop is shown in Tab.2, processing YF-xx two stage impeller as an example, the processing technology used is shown in Tab.3, the finished prototype is shown in Fig.1.

The tool parameters and processing technology of Tab.1 and Tab.2 can only be a reference, with the development of society and the progress of science and technology, new-style cutting tool material with excellent performance will emerge, processing method will be better, and the machining quality and efficiency will be greatly improved.

Tab.2 Titanium alloy commonly used machining processes

\begin{tabular}{|c|c|c|c|c|c|}
\hline $\begin{array}{l}\text { Mater } \\
\text { ial }\end{array}$ & $\begin{array}{l}\text { Cutti } \\
\text { ng } \\
\text { tool } \\
\text { mate } \\
\text { rials }\end{array}$ & $\begin{array}{l}\text { Geometric parameters of cutting } \\
\text { tool }\end{array}$ & $\begin{array}{c}\text { Sp } \\
\text { eed } \\
\mathrm{m} / \\
\mathrm{mi} \\
\mathrm{n}\end{array}$ & $\begin{array}{c}\text { cutting } \\
\text { output } \\
\mathrm{mm}\end{array}$ & $\begin{array}{l}\text { cuttin } \\
\text { g } \\
\text { comp } \\
\text { ound }\end{array}$ \\
\hline $\begin{array}{l}\text { Tc4、 } \\
\text { Tc11、 } \\
\text { Ti5Al } \\
2.5 S n\end{array}$ & $\begin{array}{l}\text { YG6 } \\
\text { Y } \\
\text { YG6 } \\
\text { X、 } \\
\text { YG8 } \\
\text { Y' } \\
\text { YT1 } \\
5\end{array}$ & $\begin{array}{ll}\gamma_{0}=5^{\circ} \sim 10^{\circ} & \alpha_{0}=10^{\circ} \sim 15^{\circ} \\
k_{\gamma}=30^{\circ} \sim 90^{\circ} & k_{\gamma}{ }^{\prime}=5^{\circ} \sim 15^{\circ} \\
\lambda_{s}=-5^{\circ} \sim 5^{\circ} & \end{array}$ & $\begin{array}{l}30 \\
\sim \\
50\end{array}$ & $\begin{array}{c}\alpha_{p}=(3 \sim 7) \\
\text { rough } \\
\text { turning } \\
\alpha_{p}=(0.15 \sim 0 \\
\text { fine } \\
\text { turning }\end{array}$ & $\begin{array}{c}\text { water } \\
\text {-base } \\
\text { cuttin } \\
\mathrm{g} \\
\text { fluid; } \\
\text { emuls } \\
\text { ified } \\
\text { liquid }\end{array}$ \\
\hline
\end{tabular}


Tab.3 YF - xx secondary impeller machining process

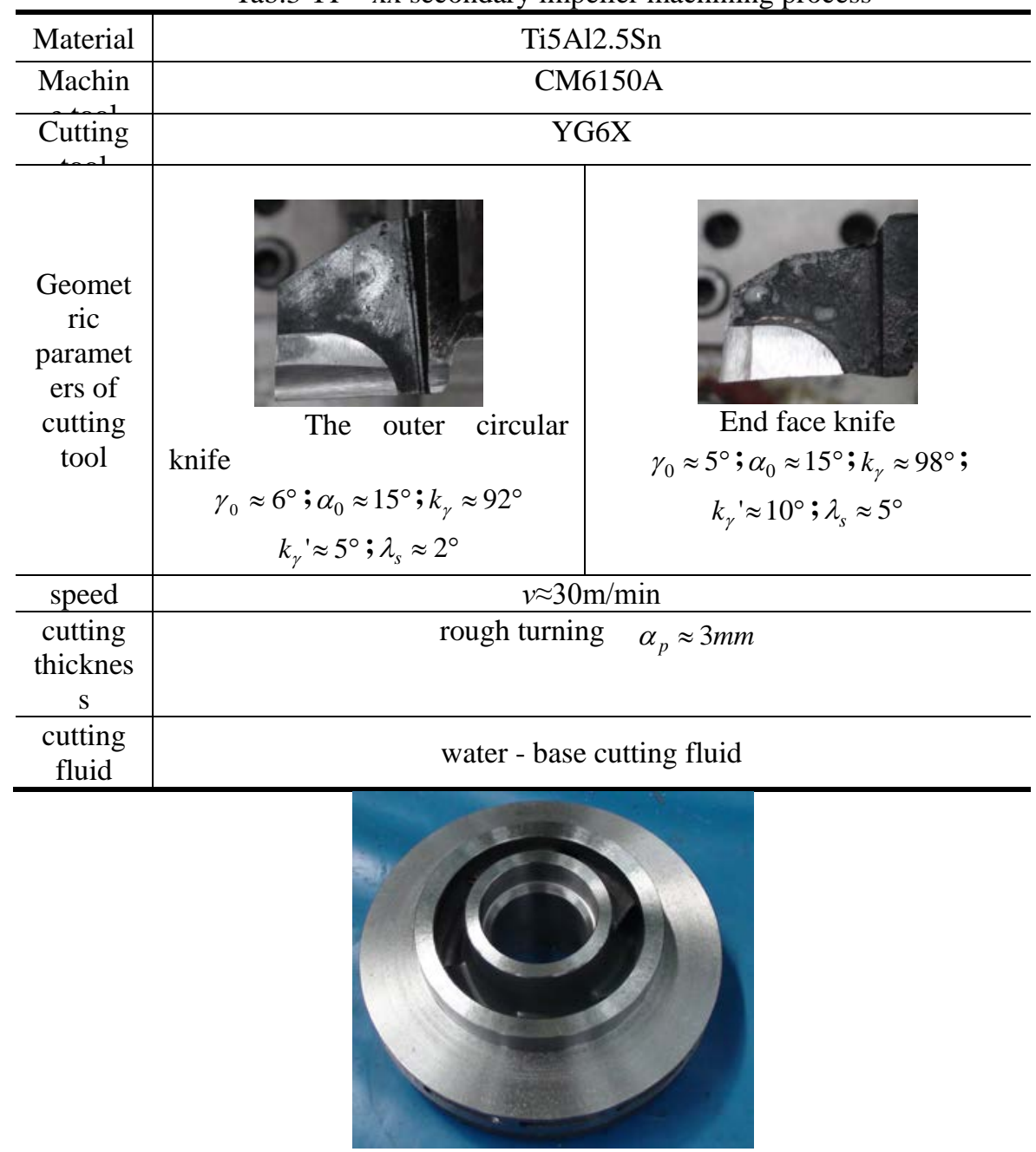

Fig.1 YF - xx secondary impeller

\section{Summary}

With the increasingly widespread application of material of difficult, its machinability study has become a main direction. There is a close relationship with the reasonable selection of difficult processing materials and cutting conditions. It has important significance to improve production efficiency, improve the process of cutting parameters selection right. This paper makes analysis on the processing performance of titanium alloy, and combines with the machining experience in actual production, introduces how to make a reasonable choice of the cutter material, cutter geometry parameter and cutting dosage, has 
certain practical value, can provide some help for the field of titanium alloy processing practitioners.

\section{Acknowledgements}

This work was financially supported by the Shijiazhuang Scientific Research and Development Plan (131080491A ) and general aviation industry key engineering laboratory open project(TY13) .

\section{References}

[1] Li Chonghe, Zhu Ming, Wang Ning. Application of Titanium Alloy in Airplane. Chinese Journal of Raremetals, Vol. 01 (2009), p. 84-91

[2] Zhang Guimu, Yang Yuhai, Zhao Shuguo. Study on the Turning of thin parts of Titanium alloy. Machinery Design \& Manufacture, Vol. 01 (2006), p. 140-141 [3] Li Shuxia, Piao Songhua. The machining process review of titanium alloy material. Winged Missiles Journal, Vol. 07 (2007), p. 57-61

[4] Zhang Yu, Luo Heping, Wu Qiushuang. Research on Machining Process of Titanium Blade. Machine Tool \& Hydraulics, Vol. 22-41 (2013), p. 1-6

[5] Zhou Zehua. Principles of metal cutting. Shanghai Scientific and Technical Publishers(1984).

[6] LeDuiqian. Metal cutting tools. Beijing: China Machine Press(1985).

[7] Lu Jianzhong, Sun Jianing. Principles of metal cutting and cutting tool. Beijing: China Machine Press(2004).

[8] Zheng Wenhu, Zhang Yulin, Zhan Mingrong. Ask hard processing material processing technology. Beijing: Beijing Publishing Company(2001). 